\title{
Investigation of the Factors Affecting College Students' English Learning Motivation and their Relationship
}

\author{
Zhen Zhou \\ Foreign Language Department \\ Jiangxi Institute of Education \\ Nanchang, Jiangxi, China, 330032 \\ E-mail: zoye100@126.com
}

\begin{abstract}
Motivation is one of the most important affective factors in the English learning. The study did a questionnaire survey and statistical analysis on the motivation of 600 college students, to explore the factors influencing English learning motivation of college students and their inner relationship. The results show that learning motivation and learning interest are closely related, learning motivation and test anxiety are negatively related; The relationship between learning motivation and will power is complex, while the students with strong willpower have relatively clear learning motivation, but as for those whose motivation is clear, their will-power is not necessarily strong; Clear learning motivation can improve the students' learning initiative and self-consciousness, and enhance the confidence of learning English. Through the investigation of the current situation of college students' learning motivation and analysis with the interest and selfconfidence, anxiety, and will-power, it provides scientific basis and suggestions for improving the quality of English teaching in higher vocational colleges.
\end{abstract}

Keywords- motivation; interest; self-confidence; anxiety; will-power

\section{INTRODUCTION}

Motivation is the main affective factor affecting the foreign language learning $[1,2]$. It is the most active factor among many individual factors of the language learning, and also is one of the most important factors deciding the success or failure in the language learning [3]. In the field of educational psychology and the second language acquisition, learning motivation research has attracted wide attention of experts and scholars [4-7]. The foreign language learning motivation and other affective factors are closely linked. The current researches on the learning motivation at home and abroad are mainly focused on studying the change and influencing factors of motivation, learning motivation and self-identity[8], learning strategies[9], teachers' support[10], teachers' behavior[11], learning behavior[12], the ability of autonomous learning[13], the idea of learning [14], learning [15], performance[16], anxiety [17], gender difference[16], goal setting[18], learning persistence [19-21], and the relationship between all sides of self-efficacy, in addition to motivation classification[22-24, 7]. In these studies, most is the study of interaction between motivation and single factor, but there is little research on the factors of motivation and self-confidence, will, attribution, and anxiety [25-28].

This article selects three vocational colleges in Jiangxi Province: Jiangxi Institute of Education, Jiangxi Modern Polytechnic College, and Institute of Blue Sky to carry out the empirical quantitative study on vocational college students' learning motivation. Through the questionnaire survey analysis on learning motivation of the college students, the article probes its relationship with interest, selfconfidence, anxiety and the will, and attempts to find a breaking point in motivating students in the English learning, so as to provide a scientific basis and teaching suggestions for improving the quality of the English teaching in the higher vocational colleges.

\section{RESEARCH METHODS}

\section{A. Subjects}

The subjects are sophomores in the business English major in the Jiangxi Institute of Education, Jiangxi Modern Polytechnic College and the Blue Sky Academy.

\section{B. Instrument}

In order to understand the relationship of English learning motivation and self-confidence, will, attribution, and anxiety of English majors' in the higher vocational colleges, this study adopts both qualitative and quantitative research methods, through the questionnaire survey, interviews, data collection, and statistical analysis via the crossover statistics.

The quantitative research: The questionnaire is designed by the author and shows high validity and reliability by pretest. Altogether there are 600 copies of questionnaire distributed in class and 585 effective copies back on the spot, and the efficiency percentage is $97.5 \%$.

The qualitative research: interview. 10 students are randomly selected in each school, and a total of 30 students will be chosen as the interview objects. Each interview lasts 5 minutes. The interview intends to make a reasonable explanation for filling the questionnaire.

\section{THE FINDINGS AND ANALYSIS}

In all respondents, only $57 \%$ of the students' learning goal is clear, $40 \%$ of the students' learning goals are not clear, while $3 \%$ of the students have no learning objectives. 
Many college students' learning in a confused state, and they do not know why to learn and what to learn. In a sense, this reflects a fact that there is a big gap between the college learning and the future job hunting and students are not confident with their future. This can be largely attributed to the college students' own English achievement situation. College students' English level is very limited and poor and many students have no clear study goal and plan and they are accustomed to their parents' preference and guidance.

\section{A. Motivation and Interest}

When the learning motivation is clear, $46 \%$ of the students think that learning English is interesting, 53\% of the students think that their learning interest is just so-so; and when the motivation is not clear, only $13 \%$ think that learning English is fun, $68 \%$ feel that learning interest is just so-so, and the ratio of those who think that learning English is interesting increases, from $2 \%$ to $20 \%$. This indicates that to some degree, the clearer motivation, the more interest students have in learning English. But this is not absolute rule. Since to many students who have clear motivation, their English learning interest is not necessarily high.

Correspondingly, among those students who are interested in learning English, $84 \%$ of the students' learning motivation is very clear, only $16 \%$ of the students' learning motivation is not clear, and no students' motivation is not clear; In those students whose interest is just so-so, the percentage of the students whose learning motivation is clear drop from $84 \%$ to $52 \%$, the ratio of clear learning motivation increases from $16 \%$ to $47 \%$; In the students with absence of English learning interest, only 9\% think that learning motivation is clear, $73 \%$ think that motivation is not so clear, $18 \%$ think that motivation is not clear. From the above it can be concluded that those interested in English also have comparatively clearer learning motivation. Therefore, there is a good relationship between students' learning motivation and interest in learning English, and learning motivation can stimulate students' interest in learning English to a certain extent.

\section{B. Motivation and Self-Confidence}

Because the vocational college students' English level is low, most of the students think that learning English is difficult. In the surveyed college students, $71 \%$ of the students think that learning English is difficult, $20 \%$ of the students think it very difficult to learn English, and only 9\% of the students think that learning English is not difficult. This objectively reflect the reality that vocational students' English level is fairly poor and even English majors' English academic achievement is poor. As an investigation reveals that vocational college English major sophomores, the percentage of passing CET Band 4(China's college English test) is only $33 \%$.

When the learning motivation is very clear, $12 \%$ of the students feel that learning English is not difficult, $77 \%$ feel that English learning a little difficult, only $11 \%$ of think it is very hard. When the motivation is not clear, the ratio of who think that English learning is very difficult increases significantly, from $11 \%$ to $28 \%$. Those unmotivated students all think that learning English is very difficult. Among those who think learning English is not difficult, $78 \%$ of the students' learning motivation is very clear, only $22 \%$ of the students' learning motivation is not clear, no students with no clear motivation. Among those who think that learning English is a little difficult, 57\% have very clear learning motivation, $38 \%$ do not have clear learning motivation. As for those who think it very difficult to learn English, 30\% have clear learning motivation, $55 \%$ of the students' learning motivation is not so clear, and 15\% students' learning motivation is not clear. Thus no matter whether the motivation is clear or not, most students feel English is hard, but those who think English is not hard have clearer learning motivation.

Clear learning motivation can enhance the confidence of learning English and enable students to actively participate in the classroom learning. The survey finds that the three groups of students with clear learning motivation, not so clear motivation and no clear learning motivation, the percentage of the students who can be active to speak and answer questions of the teacher's and do not care no matter right or wrong account for $16 \%, 10 \%$, and $0 \%$, those who will raise their hands to speak only after determining the correct answer account for $67 \%, 63 \%$, and $33 \%$ respectively, those students who keep silent account for $18 \%, 28 \%$, and $67 \%$. Students with clearer learning motivation can perform a lot more confidently in answering the teacher's questions in class. Clear learning motivation can drive students' learning enthusiasm and fill students with more confidence and willingness to participate in class interaction.

As for the three kinds of students who can be active to answer teacher's questions not caring whether the answer is right or wrong, who will raise their hand after making sure of the correct answer, and who keep silent, the percentage of the students who have clear learning motivation is $69 \%, 59 \%$, and $44 \%$ respectively, which decreases. This displays that students with clear motivation are also more confident when answering the teacher's questions. The proportion of those whose motivation is not so clear account for $31 \%, 39 \%$, and $48 \%$, and as for those whose learning motivation is not clear, the proportion account for $0 \%, 2 \%$, and $9 \%$. These two situations form sharp contrast with the first situation, as the figures increases and this shows that students with less clear motivation are less and less confident to answer teacher's questions. Therefore learning motivation and self-confidence is positively correlated, the clearer the learning motivation, the more confident students feel, and vice versa.

\section{Motivation and Anxiety}

Among the three groups of students with clear learning motivation, not so clear motivation and no clear learning motivation, the percentage of the students who can answer teacher's questions well is only $9 \%, 5 \%$, and $0 \%$ respectively. Those who are nervous when answering the teacher's questions is $86 \%, 78 \%$, and $0 \%$.The students who are very tense to answer the question is $5 \%, 18 \%, 100 \%$ respectively. In the three groups of students who can answer the teacher's question well, who can answer the teacher's question with some tension, and who answer the question 
very nervously, the proportion of very clear learning motivation account for $71 \%, 61 \%$, and $23 \%$ respectively, not clear learning motivation is $29 \%, 39 \%$, and $54 \%$ respectively; the proportion of not clear motivation is $0 \%, 0 \%$, and $23 \%$ respectively. Thus learning motivation is negatively related to the class anxiety of answering questions.

Among the three groups of students with clear learning motivation, not so clear motivation and no clear learning motivation, the percentage of the students who show very nervous in the examination is respectively $4 \%, 13 \%$, and $33 \%$, who are a little nervous in the exam account for $74 \%$, $70 \%$, and $33 \%$ respectively, the student who are not nervous and do not care for performance account for $11 \%, 13 \%$, and $33 \%$; prepared and confident students account for $12 \%, 5 \%$, and 0; Among the four kinds of students who are very nervous in the examination, who are a little nervous, who are not nervous and who are prepared and confident, the students whose learning motivation is clear account for $25 \%$, $59 \%, 0 \%$, and $77.8 \%$, students with not clear learning motivation account for $63 \%, 39 \%, 42 \%$, and $22 \%$. The students with no clear learning motivation account for $13 \%$, $1 \%, 8 \%$, and $0 \%$. Thus there is negative correlation between learning motivation and test anxiety.

\section{Motivation and Will-power}

Clear learning motivation to a large extent, can help students take the initiative to find ways to improve English learning. In the survey, when the learning motivation is clear, $74 \%$ of the students think that they could find ways to improve their English learning, and if the motivation is not clear, the proportion drops to $50 \%$. Among those students who can find the method to improve their English learning, $68 \%$ of the students think that learning motivation is very clear, only $32 \%$ think that learning motivation is not clear. In those that can't find English learning method, $40 \%$ of the students' learning motivation is clear, $53 \%$ of the students' learning motivation is not clear, $8 \%$ of the students' learning motivation is not clear.

Clear learning motivation can improve the learning initiative. In the survey, in the students whose learning motivation is clear, the students who can be perseverant in learning English rates $56 \%$, while the proportion of the students who learn just because of thinking of learning in the classroom or before the test are respectively $33 \%$ and $11 \%$. Among the students whose learning motivation is not so clear, the perseverant students account for only $23 \%$ and the percentage of the students who study only when they want in the classroom and before the exam occupies respectively $53 \%$ and $25 \%$.

Among those whose learning motivation is not clear, there are no persistent students. By contrast, in the three types of students who can persevere in studying, learn English just when they want in the classroom and before the exam, the students with clear learning motivation account for $78 \%, 45 \%$, and $35 \%$, the students with not clear learning motivation account for $30 \%, 54.8 \%$, and $65 \%$.

Among the three classes of students with clear learning motivation, not so clear learning motivation and no clear learning motivation, the rate of students who can complete the learning plan account for 30\%, 5\%, and 33\%, those who can make their own efforts but only partially complete the learning task account for 53\%, 63\%, and $0 \%$. Generally, the proportion of those who can not finish the learning plan account for $18 \%, 33 \%$, and $67 \%$.

In the three categories of students who can complete the learning plan, who can make their own efforts but generally can not finish the learning plan, and who generally can not finish the learning plan, those whose learning motivation is clear occupies respectively $85 \%, 55 \%$, and $38 \%$, those whose learning motivation is not so clear account for $10 \%$, $46 \%$, and $54 \%$ respectively, and the percentage of those with no clear learning motivation is $5 \%, 0 \%$, and $9 \%$ respectively.

The clear learning motivation can aid students in overcoming the difficulties in the English studies in a certain extent The survey finds that, as for those who can overcome the learning difficulty, $74 \%$ of the students have a clear study motivation, only $24 \%$ of the students' learning motivation is not so clear, and only $3 \%$ of the students' learning motivation is not clear; In the face of learning difficulties, as for "just cope with the difficulties", the percentage of having a clear learning motivation drops compared with the previous situation (rise to overcoming learning difficulties) from $74 \%$ to $53 \%$, the proportion of those whose learning motivation is not so clear is on obvious rise (rise from $24 \%$ to $46 \%$ ).

As for "give up in the face of learning difficulties", only $14 \%$ think that learning motivation is clear, up to $71 \%$ of the students' learning motivation is not so clear. In addition, when the learning motivation is very clear, in the face of learning difficulties, those who can grasp the nettle account for $44 \%$, those who can merely cope with the difficulty is $54 \%$, only $2 \%$ of the students give up; and among the students whose motivation is not clear, in the face of learning difficulties, those who can grasp the nettle are only $20 \%$, those who can merely cope with the difficulty are $68 \%$, and $13 \%$ students will give up. The relationship between learning motivation and will power is complex. Those students who have strong willpower also have clear motivation, but when the motivation is clear, willpower is not strong. This suggests that current vocational college students' will power level is not high.

\section{CONCLUSION}

The results of the survey show that learning motivation is positively correlated with learning interest and confidence, and is negatively correlated with anxiety. Besides the findings demonstrate that the relationship between the learning motivation and will power is complex, students with strong willpower relatively have strong motivation, but motivated students' willpower is not strong. Clear learning motivation can improve the students' learning initiative and self-consciousness, and stimulate students to actively find methods to overcome English learning difficulties.

Therefore, on the one hand, teachers can improve students' learning motivation level through the experimental training of motive, and further improve students' interest and confidence in the English learning, strengthen their willpower, and reduce the class anxiety and test anxiety. On 
the other hand, teachers can also adopt some flexible teaching strategies to stimulate students' interest in English learning, nurture students' self-confidence, and train students through special tasks to temper their willpower, improve students' learning autonomy and initiative, and take the factors which affect the learning motivation as the breakthrough point to improve students' learning motivation level And ultimately enhance vocational college students' English achievement and the English teaching quality in the higher vocational colleges.

\section{ACKNOWLEDGMENT}

This study was financially supported by the Jiangxi Education Science "12th Five-Year" planning issues (11YB104), Chinese Society of Education Foreign Language Education Committee "Twelfth Five-Year" Plan Year 2012 issues (NAFLE0112014), and foreign language teaching and research project (key project) of annual national basic education (2012-2013) (JJWYZD2012030).

\section{REFERENCES}

[1] H. Dulay, M. Burt and S. Krashen, Language Two. New York: Oxford University Press, 1982

[2] Dingfang Shu and Zhixiang Zhuang. Modern Foreign Language Teaching - Theory, Practice and Methods (Revised Edition) [M]. Shanghai: Shanghai foreign language education press, 2008. (in Chinese)

[3] Jiongying Li, "Action research: an overview, motivation and application," Journal of Sichuan International Studies University, vol. 19, June.2003, pp. 134-138. (in Chinese)

[4] R. C. Gardner and W. E. Lambert. Attitudes and Motivation in Second Language Learning. Rowley, MA: Newbury House, 1972.

[5] Z. Dornyei, "Motivation and Motivating in the Foreign Language Classroom," Modern Language, vol. 78, Mar. 1994, pp. 273-284.

[6] Chuming Wang, "The Two Big Influencing Factors and the Foreign Language Learning," Foreign Language World, vol. 32, June. 2001, pp. 8-12. (in Chinese)

[7] Xiaomin Wang and Wenzhong Zhang, "The Analysis of Current Research Situation of English Learning Motivation in China," Foreign Language World, vol. 46, Apr. 2005, pp. 58-65. (in Chinese)

[8] [8] Lu Liu and Yihong Gao, "Motivation and Self-identity Changes a Tracking Survey of Comprehensive University English Majors in the Third Grade," Chinese language, vol. 25, Jan. 2008, pp. 18-21. (in Chinese)

[9] Huihui Su, "The Differences of the Students' English Learning Motivation and Strategy at Different Stages," Modern Education Science, vol. 29, May. 2009, pp. 47-49. (in Chinese)

[10] Haoliang Zhu and Shengtao Wu, "The Change Trend of English Learning Motivation of Junior Middle School Students and Its Relationship with Teachers' Support," Curriculum. Textbooks-Teaching Methods, vol.30, Aug. 2010, pp. 58-63. (in Chinese)

[11] Yong Gan, "The Study between the Relation of Teacher Expectation Effect and English Learning Motivation," Teaching and Management, vol. 156, Feb. 2007, pp. 60-61. (in Chinese)
[12] J. B. Biggs, "Individual Differences in Study Processes and the Quality of Learning Outcomes," Higher Education, vol. 12, Aug. 1979, pp. 381-394.

[13] Qingquan Ni. "The Empirical Study on the Correlation among English Learning Motivation, Learning Strategies and Autonomous Learning Ability," Foreign Language World, vol. 63, Mar. 2010, pp. 30-35. (in Chinese)

[14] A. D Cohen, Strategies in Learning and Using a Second Language. Beijing: Foreign Language Teaching and Research Press, 2000.

[15] Xiangyang Zhang and Hong Shuqiu, "Study, Motivation and Learning Achievement - Case Study of College Students of the English Education Major Who are Upgrade from Junior College Student to University Student," Chinese Distance Education, vol. 32, Jan. 2000, pp. 21-24. (in Chinese)

[16] Jidong Guo, "The Research of the relationship among English learning motivation, englsih achievement, and gender," Foreign Language Research, vol. 57, May. 2009, PP. 42-49. (in Chinese)

[17] Mei Hao and Ruoping Hao, "The Research on the Relationship among English Proficiency, Achievement Motivation, and State anxiety," Foreign Language Teaching and Research, vol. 33, Feb. 2001, pp. 111-115. (in Chinese)

[18] Xiaohu Yang, Renlun Ding, "The Dimension Structure Types of College English Listening Learning Motivation and the Relationship with Their Listening Learning Behavior," Modern Foreign Language Listening, vol. 27, Mar: 311-317. (in Chinese)

[19] Xiaoqing Qin, "Study on the Significance of Motivation Theories on Foreign Language Study," Foreign Language Learning, vol. 97, Apr. 2002, PP. 74-79. (in Chinese)

[20] Xiaoqing Qin and Qiufang Wen, “The Internal Structure of College Non-English Majors Learning Motivation," Foreign LanguageTeaching and research, vol. 34, Jan. 2002, pp. 51-58. (in Chinese)

[21] H. Douglas Brown, Principles of Language Learning and Teaching. Prentice Hall Inc.,1987.

[22] Qiufang Wen, "The Theory of English Learning Strategies. Shanghai: Shanghai foreign language education press, 2000. (in Chinese)

[23] R. Ellis, The Study of Second Language Acquisition[M]. Cambridge: Cambridge University Press, 1994.

[24] Xiaoxiao Chen and Xinghua Guan, "Influence of Computer Literacy and English Learning Motivation on Network English Learning Behavior - Exploration of English Study Motivation and Behavior Patterns based on Computer and Network," Foreign Language Teaching and Research, vol. 139, Aug. 2007, pp. 34-37. (in Chinese)

[25] Yihong Gao, "Undergraduate English Learning Motivation and Selfidentity Changes," Foreign Language Teaching and Research, vol. 36, May. 2003, pp. 25-35. (in Chinese)

[26] Ruirong Lu, "The Relationship between Teacher Behavior and Students' English Learning Motivation," Chinese Adult Education, vol. 79, Mar. 2005, PP. 64-65. (in Chinese)

[27] Huifang Hua, "Discussion on English Learning Motivation and Strategy Research,” Foreign Language World, vol. 147, Mar. 1998, pp. 44-47. (in Chinese)

[28] Qiufang Wen, "Change Rule and the Characteristics of English Learners' Motivation, Concept, and English Learning Strategies," Foreign Language and Foreign Language Teaching, vol. 34, Feb. 2001, pp. 105-110. (in Chinese) 